\title{
14 THE DIGITAL DIVIDE AT WORK AND HOME: THE DISCOURSE ABOUT POWER AND UNDERREPRESENTED GROUPS IN THE INFORMATION SOCIETY
}

\author{
Lynette Kvasny \\ School of Information Sciences and Technology \\ Pennsylvania State University \\ University Park, PA \\ U.S.A.
}

Eileen M. Trauth School of Information Sciences and Technology Pennsylvania State University

University Park, PA

U.S.A.

\begin{abstract}
The information society has often been described as a meritocracy that enables a level playing field for all participants. From this perspective, individuals from underrepresented groups can make it alongside individuals of wealth and privilege. All that is necessary is education and training, perseverance, and painstaking effort. But if, as some argue, it is not a level playing field, then how do various underrepresented groups cope and compete within this power structure? To find this out, a critical analysis of the responses from underrepresented groups to the dominant discourses about power and IT was carried out. A conceptual framework based upon a study of African-American men and women in low income urban communities was applied to the findings of two different studies of gender in the IT profession. The results show a consistent pattern of response across underrepresented groups. In addition, these findings suggest that positive interventions can be applied across underrepresented groups so that IT does not become simply the latest mechanism for stratifying society.
\end{abstract}

The original version of this chapter was revised: The copyright line was incorrect. This has been corrected. The Erratum to this chapter is available at DOI: 10.1007/978-0-387-35634-1_28 


\section{INTRODUCTION}

In classic works on the topic, the information society has been described as a meritocracy (Bell 1976) that enables a level playing field. Individuals from underrepresented groups can make it alongside individuals of wealth and privilege. All that is necessary is education and training, perseverance, and painstaking effort. Bill Gates, the college dropout who went on to found one of the most successful corporations in the world, perhaps best personifies the potential of IT to level the playing field. From the boardrooms of Fortune 500 companies to the lyrics of rap music enjoyed by teens in the impoverished inner cities and the affluent suburbs, Gates has become synonymous with business savvy, technical acumen, and economic prosperity.

However, Amsden and Clark (1999) pose the evocative question: "Could Bill Gates have succeeded if he were Black?... Or impoverished?..." Or a woman (we could add)? These authors argue that Gates may be the uncharacteristic IT success story because he is typical only insofar as he enjoyed membership in a privileged American economic and social elite. The odds that he would have succeeded had his social world been that of the urban ghetto may be predicted to be extremely small. Factors such as unemployment and underemployment, and the absence of influential business contacts pose significant barriers to entry into the new high-tech information sectors and challenge the assumptions of the meritocracy.

If, in fact, there is not a level playing field, the question arises as to how various underrepresented groups cope within this alien power structure and whether there are consistent methods of coping that transcend the particular demographics of a given underrepresented group. To find this out, we took the findings from a study of power and IT among African-American men and women in low-income urban communities ${ }^{1}$ and applied them to the findings of two studies of gender in the IT profession. ${ }^{2}$ The goal was to see how the coping framework that was developed around one set of underrepresented people could be extended and applied to another underrepresented group.

In this investigation, narratives generated from the transcripts of in-depth interviews with participants in all three studies were analyzed. These narratives explore the range of ways in which the forces underlying underrepresentation

${ }^{1}$ This study involved interviews with African-American men and women taking classes at a community technology center in an inner city neighborhood in the U.S. (Kvasny 2002).

${ }^{2}$ Both studies involved interviews with women IT professionals about societal influences on their career development as IT professionals. One was conducted in Ireland (Trauth 1995, 2000). The other was conducted in Australia and New Zealand (Trauth 2002; Trauth et al. 2000; von Hellens et al. 2001). 
manifest themselves and the range of ways in which underrepresented people cope with their situations. Excerpts from selected interviews are used to punctuate the discussion of the coping themes. The underrepresented groups represented in this paper include both consumers and producers of IT. One set of informants is African-Americans in a low-income community who are attempting to learn the fundamentals of IT at a community technology center. The other set of informants are professional and working class women in Ireland, Australia, and New Zealand who aspire to full participation in the IT profession. We chose both consumers and producers of IT in order test the strength of our coping framework across different types of underrepresented groups in different countries interacting with IT in different ways. In addition, we are able to examine the digital divide from diverse perspectives.

We begin to address the research question, "How do underrepresented groups react to this discourse of power?" by discussing a framework of coping mechanisms that resulted from analysis of narratives of African-American informants. Following this, we apply the framework to another group of underrepresented people in the information society-women-in order to consider commonalities across underrepresented groups and the pervasiveness of certain coping mechanisms. We conclude by showing implications of our findings for future research.

\section{METHODOLOGY}

In this paper, we apply to new areas a theoretical framework that resulted from an ethnographic study of African-American participants in a community technology center located in a low-income urban city in the U.S. (Kvasny 2002). The study was informed by a theory of social reproduction (Bourdieu 1990), and examined the ways in which IT may serve to perpetuate, rather than ameliorate, social inequality. The researcher spent 8 months in the field during 2001, and employed semi-structured interviews, participant observation and document analysis techniques. The resulting framework emerged inductively from the data to explain the mechanisms by which informants interpreted and responded to the power discourse of IT.

\subsection{IT as a Discourse of Power: Race}

The components of this framework are beliefs, practices, and the implications of these beliefs and practices for reproducing social structures (Table 1). This framework consists of three categories: conceding to, conforming to, and challenging the power structure. 
The first category, conceding, encompasses beliefs about IT that relate to exclusion. These narratives range from resistance and militancy to more passive voluntary and involuntary separation from IT. When actors are faced with high levels of expectancy toward IT yet experience prolonged and traumatic frustration because they fail to attain these high expectancy levels, actors may produce more deeply rooted nihilistic tendencies (Cross 1971, 1978). Therefore, blindly processing more people through IT education programs, for example, may not promote economic advancement or empowerment, and may well increase political strife when it is impossible to satisfy those with a passionate sense of entitlement (Sowell 1995). West and West (1996) use the term "black strivings" to capture the yearning of African-Americans for broader economic, political, and social inclusion in the information society. However, these authors contend that African-Americans can be "betrayed by too much hoping" when these dreams are continuously deferred.

The second category is comprised of actors who conform to the power structure. Their narratives express a minimalist view of IT whereby IT is seen as a mechanism for social integration and assimilation. Their use of IT is consistent with ways in which the dominant discourse is prescribed. For instance, African-American women discussed using the computer to improve typing skills so that they could obtain clerical jobs.

Table 1. IT Power Framework

\begin{tabular}{|l|l|l|l|}
\hline Type of Response & \multicolumn{1}{|c|}{ Beliefs } & \multicolumn{1}{|c|}{ Practices } & $\begin{array}{l}\text { Implications for } \\
\text { Reproducing } \\
\text { Social } \\
\text { Structures }\end{array}$ \\
\hline $\begin{array}{l}\text { Conceding to } \\
\text { Power Structure }\end{array}$ & $\begin{array}{l}\text { View IT as a } \\
\text { cultural imposition }\end{array}$ & $\begin{array}{l}\text { Voluntary or } \\
\text { involuntary self } \\
\text { exclusion, mili- } \\
\text { tant or passive } \\
\text { resistance }\end{array}$ & $\begin{array}{l}\text { Enables powerful } \\
\text { to monopolize } \\
\text { the IT power } \\
\text { structure }\end{array}$ \\
\hline $\begin{array}{l}\text { Conforming to } \\
\text { Power Structure }\end{array}$ & $\begin{array}{l}\text { Embrace IT while } \\
\text { conforming to } \\
\text { underrepresented } \\
\text { group's stereotypes }\end{array}$ & $\begin{array}{l}\text { Minimalist } \\
\text { engagement with } \\
\text { IT }\end{array}$ & $\begin{array}{l}\text { Leaves the IT } \\
\text { power structure } \\
\text { unchallenged }\end{array}$ \\
\hline $\begin{array}{l}\text { Challenging the } \\
\text { Power Structure }\end{array}$ & $\begin{array}{l}\text { Commandeer IT to } \\
\text { chart one's own } \\
\text { usage and career } \\
\text { course }\end{array}$ & $\begin{array}{l}\text { Adaptive use of } \\
\text { IT to defy stereo- } \\
\text { types and exploit } \\
\text { new economic } \\
\text { opportunities }\end{array}$ & $\begin{array}{l}\text { Facilitates social } \\
\text { change within IT } \\
\text { power structure }\end{array}$ \\
\hline
\end{tabular}


The final category includes those attempting to change the power structure. Rather than accepting the limits of the dominant IT discourse, these actors are attempting to alter the discourse. They embrace IT as part of their strategy for social mobility. Whether in the home or in the workplace, they are challenging stereotypes and the limits being placed upon them.

\subsection{IT as a Discourse of Power: Gender}

This framework was extended to analyze the responses of women to the power discourse of IT by using narratives taken from two published studies of gender in the IT profession. The first study of gender and IT (Trauth 1995) was carried out in Ireland as part of a larger ethnographic study of socio-cultural influences on the development of the Irish IT sector. The researcher spent 11 months in the field during 1989 and 1990 and employed semi-structured interviews, participant observation, and document analysis. During interviews with 25 women working in Irish IT firms and American multinational IT firms, respondents discussed the ways in which Irish society inhibited or enhanced a woman's opportunities in the IT field.

A subsequent analysis of gender and the IT profession in Ireland, discussed in Trauth (2000), included the 60 men who were part of the larger study. During interviews of the same length, these men were asked to comment on the position of women in the Irish IT sector and offer possible explanations for the underrepresentation of women in IT, particularly at the higher echelons in the IT firms. Transcripts of all of the interviews were analyzed inductively using open coding and generated a set of 100 socio-cultural factors, six of which related to gender. $^{3}$

The findings from the study of gender and IT in Ireland point to societal and institutional factors that served to constrain women's participation in the IT sector and keep them away from the center of power. At the heart of the issue for the women in Ireland was a career-family dilemma that placed sole responsibility for child rearing upon the mother. The findings from this study of women, reinforced by the observations of men in the larger study, suggested patterns of responses to IT as a discourse of power.

The second study of gender and IT was carried out in Australia and New Zealand during 6 months in the field in 2000 (Trauth 2002; Trauth et al. 2000; von Hellens et al. 2001). Once again, semi-structured interviews with women IT professionals in these two countries, participant observation, and document

${ }^{3}$ See Trauth (2000, pp. 375-404) for an in-depth discussion of the methodology employed in this study. 
analysis techniques were employed. The purpose of this study was to explore the ways in which socio-cultural factors in the environment serve to enhance or inhibit a particular woman's participation in the IT field. This study was motivated, in part, by the results of two prior research projects: the study in Ireland and a study of women IT professionals in Queensland, Australia (Nielsen et al. 2000).

During interviews with 31 women, respondents discussed their career histories, significant influences on their career development, how they handle the challenges in their careers related to their gender, and broader themes about societal influences and possible interventions. In Trauth et al., three types of women were identified based upon their method of coping with the power structure in IT: those who unquestioningly internalized the constraints imposed upon them by the IT power structure; those who understood the IT power structure and attempted to conform to it and those who challenged the IT power structure. In Trauth (2002), a focus on the individual differences, nevertheless, reinforced the existence of patterns of response to IT as a discourse of power.

Taken together, these racial and gender groups are underrepresented on several of the key dimensions of the digital divide in the information society: generation of IT skills, ${ }^{4}$ race, gender, social position, social origin, and national origin. While the authors acknowledge that different groups experience domination in unique ways, the position taken in this paper is that there is evidence, nevertheless, to suggest similarities in the coping strategies that cut across different underrepresented groups. By taking this view, we acknowledge the need to maintain a balance between reductionism that treats underrepresented groups as a monolithic bloc, and a deconstruction that teases out the interactions by race and gender. We do this, in part, by presenting representative quotes that illustrate the theoretical position for members of the different underrepresented groups.

\section{RESPONSES TO THE POWER DISCOURSE OF IT}

In this section, we show the results of our effort to test the strength of the IT power framework by extending it beyond the original underrepresented group (race) to another group (gender). We show the application of the framework through the use of excerpts from the narratives used in the published studies. These representative excerpts illustrate the themes being addressed in the various categories of the framework. For each of the categories in the framework, themes from the original study of race (Kvasny 2002) are discussed first;

\footnotetext{
${ }^{4}$ That is, the mode of generation - through the university or at a community technology center-of digital competence.
} 
this is followed by a discussion of themes from the studies about gender (Trauth 1995, 2000, 2002; Trauth et al. 2000; von Hellens et al. 2001).

\subsection{Conceding to the Power Discourse}

People in this first category, conceding, cope by acquiescing to the power of IT. They do this by removing themselves. This occurs through voluntary selfexclusion from IT and militant resistance to it. But in so doing, these behaviors reproduce the power discourse of IT by leaving the powerful with a monopoly over IT.

\subsubsection{The Racial Divide}

Bill, an African-American male, provides a narrative that seems to depict an ethos of despair. He appears to adopt a "blame the victim" mentality that internalizes IT as a form of cultural domination that enslaves Black men. Cultural domination occurs when a collective within a society, typically the majority, is seen as having preeminent authority to function both as guardians and sustainers of the controlling value system in society. According to Mucha (1999), cultural domination is a social relation, in which the culture of a majority can exert pressure on minority cultures, aiming at their subordination or even total absorption. The terms minority and majority, here, do not apply in the numerical or statistical sense, but rather in the power sense. Majority simply means the dominant ethnic, racial, gender, or socio-economic group, while minorities are those groups that are structurally and/or culturally subordinated. Thus power relations, not statistical relations, are important here.

Interviewer: What are some of your initial impressions about the Internet?

Bill: What do I think about the Internet? It is a kind of mind destruction. It is kind of like Christmas where the media comes into your house and just takes over. The White man is invading my home through radio and TV ads. He is programming my family to want this stuff. The Black man can't afford to give his family all of this stuff. So technology becomes a nightmare for us. We really don't want no part of that shit....The Internet may be just one more thing that is being developed to not support Black interests. What does the Internet mean for our survival? 
Those whose narratives viewed IT as a cultural imposition have internalized the limits set by history and current social conditions, and decided that their participation won't improve their life chances. When asked about initial impressions of IT, Bill still saw the same closed doors, dead-ends, and limited prospects. When faced with these constant betrayals, actors such as Bill resorted to a bleak and hopeless worldview, perhaps becoming more avid believers that IT is "not for people like us." Holding on to the dominant IT discourse, they see their lack of participation as a personal failure.

However, other African-American males responded to this cultural imposition more militantly by creating alternative cultures that offer practical knowledge of how to get by and provide alternative criteria to determine self worth. In the excerpt below, a participant at the community technology center discusses African-American males who self-exclude themselves from the IT power discourse by outright rejecting IT training.

Charlene: Women are running the community. Guys are... selling drugs to make fast money. Makin' more money than they would earn legally. They're not interested in coming to the [community technology] center because they need to be on the streets wheeling and dealing. Anyway who is going to hire them when they finish [the IT courses]?

Self-exclusion is a form of subordinate adaptation employed by groups coping with inequality whereby they reject the dominant culture and carve out a space in the margins (Schwalbe et al. 2000). These alternative cultures enable groups to meet their psychic needs and find solidarity in the face of hostile dominant culture. However, alternative cultures can have the negative effect of discouraging individual striving, as in the case of some African-American males who viewed IT use as "acting White" or "doing women's work."

\subsubsection{The Gender Divide}

When applied to gender and IT, self-exclusion as a method of coping with the power structure is not so much dropping out as being forced out because of societal perceptions regarding gender, gender identity, and parenthood. For example, an Irish woman told her story about being required to leave her job when she married. She was able to return to work for a few months after her marriage but was rehired as a temporary summer employee at the minimum wage, "despite the fact that I was coming back to do exactly the job I had left to change my name!" When asked about the cultural attitude toward women working in the IT sector, a common response was that such work, at best, should 
be limited to unmarried women or married women without children. In these circumstances, women are encouraged by the dominant discourse to self-exclude from the IT workplace.

Interviewer: What is the general societal attitude toward women working [in IT]?

Patricia: It is that if jobs are scarce why have two partners working? "Isn't she married and her husband working?" If a married woman returns to work it's even worse. It's viewed as taking a job from a young, single girl. I think the underlying view is women should be kept in the menial jobs because they will be leaving them anyway.

Self-exclusion also occurs when a woman copes with the subordinate position in which the dominant discourse places her, by leaving that particular IT workplace. Charla, an Australian woman, explains how unfair managerial compensation practices systematically fail to recognize the contribution of female managers. As a consequence, she notes, women self-exclude by leaving that IT workplace.

Charla: I would say we are not valued as much. Or not always. Or we have to actually sometimes ask to be recognized financially. And with me, some other manager who was also female was not recognized financially as much as some other guys that were not even in management positions. One of the girls who was working for this group she has left, because of the lack of financial recognition. And she was quite capable and she had a very good education. But she wasn't really getting any recognition that would satisfy her. So she basically has left.

Taken together, these narratives suggest that institutional changes such as the creation of community technology centers and the entry of women into the IT workforce are far from sufficient to ensure full participation in the information society. Underrepresented groups are socialized in broader socio-cultural contexts such as homes, schools and workplaces where they are taught their place in society. Through "othering"- - the act of highlighting a group's differences in such a way as to present its members as both different from and inferior to "the norm" - the dominant group seeks advantage over the dominated groups by defining categories based on race, ethnicity, gender, and social class, and asserting that these groups are somehow deficient. These patterns of inequality reaffirm the dominant ideology of difference and make it difficult for 
members of other groups to signify fully credible selves (Schwalbe et al. 2000). In the case of the power discourse for IT, women and Blacks learn that they cannot have authority over White males. Other things being equal, therefore, they are likely to be passed over in favor of a White male in a position of authority. Consequently, the argument goes, members of these underrepresented groups are confined to subordinate and ancillary functions (Bourdieu 2001). By acquiescing to the dominant discourse, the underrepresented groups in this category reproduce the existing order, thereby giving White males a monopoly in the handling of technical objects and machines.

\subsection{Conforming to the Power Discourse}

The people in the second category, conforming, cope by attempting to assimilate into the power structure. They do this by adopting a minimalist view that IT adoption and use is a tool for social integration. Their use of IT is consistent with the limits set by the dominant discourse. But in doing so, their behaviors leave the power discourse of IT unchallenged.

\subsubsection{The Racial Divide}

African-American participants at the community technology center suggest that members of underrepresented groups view IT as a means for assimilation and integration within the information society. In these narratives, participants express concerns of being left behind and excluded from the multiple resources available on the Internet for civic, democratic, and economic engagement. Doris, for instance, espouses a powerful virtual self in which competence, self worth, and legitimacy were believed to result from the acquisition of an e-mail address.

Doris: I thought I would be the last one to have an e-mail address! I was once at a meeting and everyone in my group had an e-mail address. I was embarrassed not to have one because everyone else was a senior citizen with some sort of computer knowledge.

This senior citizen believed that digital skills would enable her to alleviate social isolation and increase her ability to participate with her peer group. As an outsider, she felt that IT skills would enable her to "cross over" into the

\footnotetext{
${ }^{5}$ The term "crossing over" is prevalent in African-American spirituals to symbolize going to heaven or a place in which there would be no suffering.
} 
computing culture where "sending e-mail makes me feel like a businessman." This participant's view reinforces the power discourse, which in this case is about the use of IT as part of a strategy that upholds the images of more privileged groups as those worthy of emulation. This is a form of identity work commonly practiced by those seeking membership in dominant groups (Schwalbe et al. 2000).

Others view IT skills not as a mechanism for copying the privileged, but as a method for retaining their self-esteem. Parents, for example, described themselves as the forgotten generation. Their world of experience offered narrow opportunities to acquire IT skills; however, they faced increasing pressures to compete in a world that demands IT proficiency. As a consequence, they carry the stigma of catching up in a race they previously were not able to enter. Now they are at least in the race, but they must enter at the tail end of the line. Technology was therefore revealed to people like Sherry, a young single parent, as something that smart people do naturally.

Sherry: I like computers but I would like them more if I knew how to use them. People who know something about computers probably think I am dumb.

While some of the African-Americans like Doris were striving to gain a foothold in the IT power structure, others like Sherry were struggling to recover their dignity. The narratives of individuals who cope by conforming to the existing order of things express a compelling understanding of the social power conveyed by IT but demonstrate a somewhat limited ability to manage within this power structure.

\subsubsection{The Gender Divide}

The perception that IT is "something not quite for them" was held by women as well. Some felt like interlopers in the IT field. One context in which this perception was expressed was in discussions about the low numbers of women in Australia and New Zealand who take IT courses in the university. In the narrative below, Karen attempts to explain the reasons why.

Karen: Yes I guess the numbers, I think that's true. I think students drift away from computer science.... There is a whole lot of stuff to go with people's perceptions of how smart you need to be in order to do it or prior experience in the case of IT that helps you get somewhere and I haven't got that experience and I can't do it. They think there's deceit in which there is a 


\begin{abstract}
hidden curriculum in IT that girls don't have as much enthusiasm so it drives some people away. Not gender biased curriculum just the stuff I hadn't done when I was younger and therefore I am behind now. I think there is a perception that that's a barrier and therefore I won't bother pushing past it...I think there are gender patterns in that kind of behavior and I think they play out for students in their willingness to progress through the different levels.
\end{abstract}

In their unwillingness to push against the perceived barriers, these women are conforming to the power discourse of IT.

Once in the IT workforce, women also conform to the power discourse by accepting the terms under which the may participate. If they are parents, they accept that they are the ones responsible for their children even if they have full time jobs as demanding as their husbands'. If women are expected to be fully responsible for childcare, then - if one is conforming to the power discoursein order to participate in the IT workforce, a woman can cope in one of two ways. One choice would be to decide not to have children. Sean, an Irish IT manager, articulates the dominant discourse in his comments about women working in IT.

Sean: I think that in the IT industry where there is a strong demand for flexible time, sometimes very long working hours, practically speaking, it's difficult if it's working mothers with childcare duties. It's not as easy. For instance, Fiona is to be in the UK for the next three months. She couldn't do that if she has a family. She couldn't ring up the husband and say "I'm going to the UK this evening for two days. I won't see you until Friday." The nature of the IT industry, I think, is that that happens. You have to respond, you have to go.

The other choice a woman has is to scale back her professional aspirations. In doing so, she conforms to the dominant discourse by staying in her place.

Julie: Of course there is that women are not putting themselves forward. But the real question is "Why?" That's the answer you always get from men. "They're not putting themselves forward," "They're not ambitious," "They will not do it." But, of course, we know that there is a complex set of reasons why that is the case. Some of it has to do with the amount of hours and commitment that is required in an industry such as ours. On personal choice they do not want to make that decision.... Most 
of the women that you talk to, that I talk to, it's not about not wanting to work or not wanting to get on. Of course they want to get on, same as anybody else, and realize their potential. But they're very concerned and guilty about what effect that's having on their children, and they will pull back. That'll go on the back burner.

Through the experience of a gendered and racially oriented social order and explicit reminders addressed to them by their peers and colleagues, members of these underrepresented groups internalize the principles of the dominant discourse which leads them to see the existing social order as natural or normal. In a sense, they anticipate their social destiny (Bourdieu 2001). Women refuse the careers from which they are anyway excluded while rushing toward those that they are being socialized to assume. In a similar manner, African-Americans at the community technology centers viewed IT as a communicative tool used by the privileged, not a vehicle that African-Americans could employ for economic and political empowerment. Thus, in their compliant use of and response to IT and its associated discourse, the underrepresented groups in this category also ratify and reproduce the social order.

\subsection{Challenging the Power Discourse}

The people in the third category, challenging, cope by attempting to wrestle control of the power discourse away from the dominant group. They do this by employing the technology in new ways for new purposes, and by charting their own career trajectories. They refuse to accept the limits imposed by the dominant IT discourse. In doing so, their behaviors are forcing social change.

\subsubsection{The Racial Divide}

Contrary to the digital divide statistics that report relatively less IT use by older Americans (NTIA 2002), senior citizens were the most active and innovative IT users at the community technology centers. Although most senior citizens initially came to the centers with no immediate purpose, over time they began to realize that IT offered them opportunities. Pearl provides a narrative that reflects a view of IT as a vehicle for "social flying" as it helps the individual to defy the gravity of the social hierarchy.

Pearl: I want to make sure that you understand how important this [community technology center] is to us [senior citizens]. 
It is giving us a new lease on life. It increases my thoughts, and my ability to learn. The environment is very encouraging. I now have faith and hope. Now I understand that there are things out there for us, as we get old. The [community technology center] fills a great need. We seniors are now becoming qualified homebodies. We can fill these jobs.

For Pearl, the community technology center serves as a cultural space from which senior citizens can resist and transform the IT power structure. Martin and Nakayama (1997) note that cultural space is both a particular location that has culturally constructed meanings, and a metaphorical place from which we communicate. Employing the latter conceptualization of cultural space, Pearl uses the metaphor of "qualified homebodies" to create a standpoint from which to resist and transform the IT power discourse. The goal is not merely to survive or to fit in or to cope; the goal is empowerment and opportunity for senior citizens in the information economy.

\subsubsection{The Gender Divide}

For women in the IT profession, challenging the status quo is sometimes quite overt and other times more subtle. Nuala told a number of stories about her experiences in challenging the status quo in Ireland. Her first challenge was to obtain an IT education:

Nuala: [When we were presenting our final project] the lecturer asked who had done what. I started out talking first but the lecturer didn't seem to be paying any attention to me. He wasn't looking at me. He wouldn't make any eye contact. It was going so bad that Sean jumped in and finished my statement to save our grade. Because of that, I almost didn't pass. I was told by the other students that Sean and Tom were "carrying me." And everyone believed these guys were doing all the work.

A subsequent challenge was to obtain an equal place in the IT profession. In the process of challenging the dominant discourse and the social order, she also changed herself.

Nuala: People wondered how I could advise people about computing since I was a woman. At [my firm] I was the only technical woman in the beginning. Boys are taught how to brag, to 
exploit and brag. There was this guy at work who would always hassle the women. No matter how I distinguish myself, I can never escape being a woman. My sister-in-law noticed that I am now more assertive, bragging about my skills now.

In the Australian IT sector, Virginia's way of challenging the power discourse has been to be strong and refuse to be victimized. Instead of placing responsibility on institutional barriers, she criticizes women who fail to fight the system. Like Nuala, Virginia believes that in order to prevail against the dominant discourse, women have to behave differently.

Interviewer: Do you have the same experiences as these two women [who chose to leave the company]?

Virginia: No, I don't let myself. See, I really believe that you can be a victim of something or you can move on or do something about it....I mean this gender problem that is perceived in society, I wonder how much of it would you be able to eliminate if women were strong and did something about it. Now what I can't answer-and I've wondered this-have I become the person I am because I needed to survive in business because I am ambitious? To fulfill my ambitions have I subconsciously.... That in order to be like that, I have got to be really task oriented. I've really got to not worry about, you know, the touchy feely things in life and I have really got to get on with the job and get to the top if there are any problems. Like most men do or most...but see up until now I wouldn't have said that most men do. "Most people need to do," I would have said generally. Or is it part of my personality that I am like that, more like a male than a female as you put it. And that helps me survive in business.

Virginia has little patience with women who complain about their circumstances but who refuse to fight. In some respects, she sets herself apart from other women. Perhaps she even holds herself above them. Thus, even as her behavior is directed at challenging the power discourse, her actions play a role in reproducing inequality for other women (Schwalbe et al. 2000). In her singleminded view of fighting the status quo by emulating the dominators as the only alternative, she excludes and discredits those women who are unable or unwilling to challenge the dominant discourse or to respond to power with power. Nevertheless, from an individualistic perspective, her approach is 
empowering. It facilitates her challenge to the status quo and enables her to succeed.

Despite the societal messages that members of underrepresented groups may have received about "their place" in the IT power structure, some refuse to acquiesce. People such as Virginia challenge this presumed social order by embracing IT as a vehicle for personal change, upward mobility, or career advancement. The narratives of individuals who cope by challenging the existing order of things convey potency: both personal empowerment and an understanding of the social power conveyed by IT.

\section{CONCLUSION}

Even as these narratives show different responses to IT as a vehicle for the transmission of power, we found consistent patterns of coping across the discourses that were examined in this study. For example, some underrepresented people do not see themselves as being able to even embark upon the IT journey. Others reinforce the power discourse by adopting the limited roles assigned to them by virtue of their membership in a particular racial, gender, or socio-economic group. Still others refuse to accept the status quo. Instead, they take a seat at the table that may not have been set for them.

This analysis of the power discourse about IT and the coping strategies practiced by underrepresented groups has two main implications for further research. First, our analysis suggests that the domain of power and IT is a varied landscape. The African-Americans, for instance, experience a digital divide within the informational city (Castells 1991). The informational city is one of socio-spatial segregation that is polarized between highly valued groups on the one hand, and devalued groups threatened with social and economic irrelevance on the other. Looking more broadly across societies, women in this study experience a digital divide within the IT sector of industrialized nations. Even within industrialized countries like Australia, Ireland, New Zealand, and the U.S., notable stratification in digital opportunities still exist among citizens and these divides follow broader patterns of social inequality (Norris 2001).

This paper highlights the need to understand how the IT power discourse is enacted for various members of different underrepresented groups in different countries. It is not as simple as giving everyone a laptop and expecting instant engagement with the information age. Hence, further research into this area should move along the lines of examining personal narratives about how power is internalized and responded to at the individual level of analysis. From there, we could begin to construct generalizations about subgroups. 
Second, our analysis challenges a common assumption that IT is automatically a vehicle for upward mobility. Instead, we found that the conduct of an actor's adoption and use of IT for social mobility varies depending on whether IT is internalized as part of an impossible, possible, or probable future. Behavior tends to be governed by what is reasonable to expect for "people like us." Therefore, further research must take the unique characteristics of different underrepresented groups into consideration. The challenges are to understand how the new technology is communicated, and how it is positioned so as to enable underrepresented groups to understand that IT can, in fact, serve as a vehicle for social mobility. As our interactions with IT increase, the social and economic implications of IT use by underrepresented groups becomes critically important.

All technologies have unanticipated and unintended effects, and a central function of policy-making is to avoid or minimize undesirable outcomes (McChesney 1996). The digital divide policy, for the most part, has been largely confined to the issues that the "have nots" pose for governments and big business, and how the have nots are to be integrated into the information society. This applies both to the racially underserved in the information society and the women who are underrepresented in the IT workplace. The implication is that corporate, educational, and government institutions define the terms of participation in the information society. Given this situation, some members of underrepresented groups will develop strategies to adapt to the power structure. Others will develop modes of resistance. Still other will develop strategies to challenge the status quo. Consequently, we have developed a framework that helps us to better understand these responses to the power discourse of IT.

The ultimate goal of research into the digital divide in the information society is to develop and implement interventions to alter the power discourse that excludes people from engagement with IT on the basis of individual characteristics such as gender and race. A first step in that direction comes from a better understanding of IT as a discourse of power experienced by underrepresented groups. The purpose of this paper has been to facilitate that step by presenting a conceptual framework that enables a clearer view of the discourse of power that is engendered by IT.

\section{REFERENCES}

Amsden, A. H., and Clark, J. C. "Software Entrepreneurship Among the Urban Poor: Could Bill Gates Have Succeeded if He Were Black?... Or Impoverished?,"in D. Schon, B. Sanval, and W. J. Mitchell (eds.), High Technology and Low-Income Communities: Prospects for the Positive Use of Advanced Information Technology. Cambridge, MA: MIT Press, 1999.

Bell, D. The Coming of Post-Industrial Society: A Venture in Social Forecasting. New York: Basic Books, 1976. 
Bourdieu, P. Masculine Domination. Stanford, CA: Stanford University Press, 2001.

Bourdieu, P. Reproduction in Education, Society and Culture ( $2^{\text {nd }}$ ed.). Thousand Oaks, CA: Sage Publications, 1990.

Castells, M. The Informational City: Information Technology, Economic Restructuring, and the Urban-Regional Process (2md ed.). Oxford, UK: Blackwell Publishers, 1991.

Cross, W. "The Negro-to-Black Experience: Toward A Psychology of Black Liberation," Black World, July 1971, pp. 13-27.

Cross, W. "The Thomas and Cross Models of Psychological Nigrescence: A Review," The Journal of Black Psychology (5:1), 1978, pp. 13-31.

Kvasny, L. Problematizing the Digital Divide: Cultural and Social Reproduction in a Community Technology Initiative. Unpublished Ph.D. Thesis, Department of Computer Information Systems, Robinson College of Business, Georgia State University, Atlanta, GA, 2002.

Martin, J., and Nakayama, T. Intercultural Communication in Contexts. Mountain View, CA: Mayfield Publishing Company, 1997.

McChesney, R. "The Internet and U.S. Communication Policy-Making in Historical and Critical Perspective," Journal of Communication (46:1), 1996, pp. 98-124.

Mucha, J. "Cultural Domination and the Reaction to It," Sociologia (31:6), 1999, pp. 567-586.

National Telecommunications Information Administration (NTIA). A Nation Online: How Americans are Expanding Their Use of the Internet. Washington, DC: U.S. Department of Commerce, 2002 (online at http://www.ntia.doc.gov/opadhome/digitalnation/index.html).

Nielsen, S., von Hellens, L., and Wong, S. "The Women in Information Technology Project: Uncovering the Pride and Prejudices," in Proceedings of the Sixth Australasian Women in Computing Workshop, Brisbane, July 2000.

Norris, P. Digital Divide: Civic Engagement, Information Poverty and the Internet Wordwide. Cambridge, UK: Cambridge University Press, 2001.

Schwalbe, M., Godwin, S., Holden, D., Schrock, D., Thompson, S., and Wolkomir, M. "Generic Processes in the Reproduction of Inequality: An Interactionist Analysis," Social Forces (79:2), 2000, pp. 419-452.

Sowell, T. Race and Culture: A World View. New York: Basic Books, 1995.

Trauth, E. M. The Culture of an Information Economy: Influences and Impacts in the Republic of Ireland. Dordrecht: Kluwer Academic Publishers, 2000.

Trauth, E. M. "Odd Girl Out: An Individual Differences Perspective on Women in the IT Profession," Information Technology and People (15:2), 2002, pp. 98-118.

Trauth, E. M. "Women in Ireland's Information Industry: Voices from Inside," Eire-Ireland (30:3), Fall 1995, pp. 133-150.

Trauth, E. M., Nielsen, S., and von Hellens, L. "Explaining the IT Gender Gap: Australian Stories," in Proceedings of the $10^{\text {th }}$ Australasian Conference on Information Systems, Brisbane, December 2000. [CD-ROM]

Von Hellens, L., Nielsen, S., and Trauth, E. M. "Breaking and Entering the Male Domain: Women in the IT Industry," in Proceedings of the ACM SIGCPR Conference on Computer Personnel Research. New York: ACM Press, May 2001, pp. 116-120.

West, H., and Gates, C. The Future of the Race New York: Vintage Books, 1996.

\section{About the Authors}

Lynette Kvasny in an assistant professor of Information Sciences and Technology at Pennsylvania State University. Prior to her arrival at Penn State, Lynette held various information systems development and consulting positions 
at AT\&T, Bell Laboratories, Lucent Technologies, and Avaya Communications. She was selected to participate in the International Conference on Information Systems 2000 Doctoral Consortium, and she was recognized as a KPMG Doctoral Scholar in 2001-2002. Her research interests focus on socio-technical influences on information technology adoption and use in historically underserved communities. She has published several conference papers and book chapters. Kvasny is a member of the Association for Computing Machinery, the International Federation for Information Processing, and the Computer Professionals for Social Responsibility. Lynette can be reached by e-mail at 1kvasny@ist.psu.edu.

Eileen Trauth is a professor of Information Sciences and Technology at Pennsylvania State University. Prior to joining IST, Trauth taught at Northeastern University's College of Business Administration, the University of Pittsburgh, Bentley College, and Boston University. She consults and lectures on the impact of information technology on organizations and societies. She has written articles for such publications as MIS Quarterly, Telecommunications Policy, ACM Transactions on Office Information Systems, Education and Computing, Information and Behavior, Information and Management, and Journal of Systems Management. She has also published a textbook entitled Information Literacy. A visiting professor in several countries, Trauth was a Fulbright Scholar at Dublin City University where she taught and conducted research on societal influences and impacts of Irelands information economy. Trauth is a member of the Association for Computing Machinery, the International Federation for Information Processing, the Society for Information Management, and the Information Resources Management Association. Eileen can be reached by e-mail at etrauth@ist.psu.edu. 